\title{
Calangos e lagartixas: concepções sobre lagartos entre estudantes do Ensino Médio em Fortaleza, Ceará, Brasil
}

\author{
Calangos e lagartixas: conceptions on lizards \\ among High School students in Fortaleza, Ceará, Brazil
}

\author{
Daniel Cunha Passos ${ }^{1}$. Laís Feitosa Machado ${ }^{2}$. \\ Alexandre Ferreira Lopes ${ }^{3}$. Bernadete de Lourdes Ramos Beserra ${ }^{4}$
}

\begin{abstract}
Resumo: As concepções culturais influenciam as atitudes humanas em relação aos animais, e sua compreensão é essencial para se entender o impacto dos seres humanos sobre a fauna. Neste trabalho, inventariamos concepções sobre lagartos segundo estudantes dos estágios finais da Educação Básica, avaliando sua relação com o atual estado do conhecimento científico e interpretando os casos em discordância. Realizamos entrevistas com estudantes do terceiro ano do Ensino Médio sobre aspectos gerais relacionados a concepções, conhecimentos e usos tradicionais de lagartos. Entrevistamos 38 estudantes que compartilharam 85 concepções distintas. Embora muitas das concepções inventariadas tenham apresentado coerência com os conhecimentos científicos atuais, existiram algumas incongruências. De forma geral, os produtos desta pesquisa forneceram subsídios para a valorização dos lagartos, além de reforçar a necessidade da inclusão de ações de educação ambiental na Educação Básica, como ferramentas para enriquecer o conhecimento sobre a biodiversidade, bem como esclarecer e desmistificar possíveis concepções errôneas.
\end{abstract}

Palavras-chave: Ensino de biologia. Educação Básica. Lagartos. Etnobiologia. Etnoherpetologia.

\begin{abstract}
Cultural conceptions influence human attitudes towards animals and their understanding is essential to know the impact of humans on fauna. In this work, we inventoried conceptions of lizards held by students in the final stages of Basic Education, evaluating their relationship with the current state of scientific knowledge and interpreting the cases of disagreement. We carried out interviews with students of the third year of High School about general aspects related to conceptions, knowledge and traditional uses of lizards. We interviewed 38 students who shared 85 different conceptions. Although several conceptions were consistent with current scientific knowledge, there were some inconsistencies in relation to scientific understanding. Overall, our findings showed the benefits of valuing lizards, beyond reinforcing the need for inclusion of environmental education actions in Basic Education, as enrichment tools for knowledge of biodiversity, as well as elucidating and demystifying possible mistaken conceptions.
\end{abstract}

Keywords: Biology teaching. Basic education. Lizards. Etnobiology. Etnoherpetology.

\footnotetext{
${ }^{1}$ Instituto de Biologia Roberto Alcântara Gomes, Universidade do Estado do Rio de Janeiro (UERJ), R. São Francisco Xavier, 524, Pavilhão Haroldo Lisboa da Cunha, Sala 224, Maracanã, CEP 20550-013, Rio de Janeiro, RJ, Brasil. E-mail: < biologodanielpassos@gmail.com>

${ }^{2}$ Instituto de Microbiologia Professor Paulo de Góes, Universidade Federal do Rio de Janeiro (UFRJ), Rio de Janeiro, RJ, Brasil.

${ }^{3}$ Departamento de Ciências do Meio Ambiente, Instituto Três Rios, Universidade Federal Rural do Rio de Janeiro (UFRRJ), Três Rios, RJ, Brasil.

${ }^{4}$ Faculdade de Educação, Universidade Federal do Ceará (UFC), Fortaleza, CE, Brasil.
} 


\section{Introdução}

A significância dos répteis para os humanos varia muito entre diferentes culturas ao redor do mundo (VITT'T CALDWELL, 2008). O reconhecimento da importância e a valorização destes animais dependem dos tipos de relações que são estabelecidas entre eles e os seres humanos (ALVES et al., 2012a). As concepções culturais sobre os répteis, assim como as formas de manejo e os usos destes animais por comunidades tradicionais, constituem os objetos de estudo da etnoherpetologia (BARBOSA et al., 2007). Este ramo de pesquisa, uma subdivisão da etnozoologia, ainda é incipiente no Brasil (ALVES; SOUTO, 2011), no entanto, as concepções populares acerca dos répteis podem contribuir, particularmente no âmbito educacional, para a compreensão do processo de construção do conhecimento sobre estes animais, analogamente ao observado para outros organismos (COSTA NETO, 2007; RAZERA; BOCCARDO; PEREIRA, 2006; SILVA; MANFRINATO; ANACLETO, 2013).

As interações com os répteis, geralmente, surgem devido à utilidade ou aos riscos que estes representam aos humanos (ALVES et al., 2012b). Além disso, os répteis são, reconhecidamente, criaturas incitadoras do imaginário popular, estando associados a características sobrenaturais, sagradas e mágicas de diferentes povos e em diferentes épocas, por todo o mundo (CASAS ANDREU, 2000). Na África, os crocodilos (por exemplo, Deus-crocodilo Sobek) já foram cultuados (HART, 2005), as tartarugas (por exemplo, Ninfa Quelone) figuraram na mitologia clássica grega (FRANCHINI; SEGANFREDO, 2007), e a cultura asiática (por exemplo, Deus-Shiva) sempre rendeu homenagens às serpentes (THAPAR, 2006). Entretanto, apesar do elevado grau de parentesco biológico com os demais répteis, a percepção humana, especificamente sobre os lagartos, apresenta elementos singulares que os distinguem e os particularizam.

Os lagartos surgiram há cerca de duzentos milhões de anos, durante a era Mesozoica (POUGH; JANIS; HEISER, 2008). A pele impermeável, seca e revestida por escamas epidérmicas, a presença de casca envolvendo o ovo, e a fecundação interna, independente da água, consistiram adaptações que permitiram a perpetuação destes animais até os dias de hoje (ZUG; VITT; CALDWELL, 2001). Desta forma, os lagartos se diversificaram e, atualmente, constituem o grupo mais biodiverso entre os répteis, com mais de 5.500 espécies formalmente descritas, distribuídas por quase todos os ambientes terrestres do planeta, com exceção das regiões polares (UETZ, 2013). Estes animais convivem simpatricamente com os seres humanos desde épocas remotas, fato evidenciado por pinturas rupestres e artefatos arqueológicos que remetem a estes répteis. Portanto, os lagartos têm participado, direta ou indiretamente, do cotidiano dos humanos ao longo de sua história evolutiva, interagindo de diversas formas e promovendo percepções únicas.

A grande diversidade biológica dos lagartos faz com que estes organismos sejam relacionados a uma ampla variedade de símbolos. Talvez, por isso, estes animais sejam reverenciados por culturas tradicionais em todo o mundo. $\mathrm{Na}$ África, povos pigmeus acreditam que o camaleão lendário Arumei participou da criação do mundo (CASTILLO, 1993). Na Oceania, a mitologia aborígene invoca lagartos monitores para explicar as origens do dia e da noite (ROBERTS; MOUNTFORD, 1965). Na Ásia, a astrologia hindu inclui uma variedade de crenças (Gowli Shastra) que atribuem efeitos diretos da interação com lagartos na vida humana (SHUKLA, 1994). Entretanto, embora os lagartos tenham influenciado amplamente o imaginário humano ao redor do mundo, na América, sua importância nas culturas nativas parece ser menos conhecida. 
A pesquisa acerca de etnoconhecimentos específicos sobre lagartos nas Américas é relativamente escassa quando comparada às de outros grupos biológicos, estando limitada a registros pontuais, dos quais se destacam as clássicas contribuições: das tribos Apache na América do Norte, da sociedade Maia na América Central e dos índios Canela na América do Sul. As tribos Apaches reverenciavam os lagartos chamados de monstros-de-Gila (Heloderma), aos quais era atribuída a capacidade de influenciar o clima (BROWN; CARMONY, 1991). A cultura Maia, por sua vez, registrou a incorporação de lagartos de grande porte, em especial iguanas (Iguana), à dieta humana (LEE, 1996). Enquanto os índios Canela, do Nordeste do Brasil, destacaram-se por sua habilidade taxonômica em relação aos lagartos, demonstrando reconhecida capacidade de distinguir e nomear várias das espécies ocorrentes na região (VANZOLINI, 1956).

O Brasil possui, atualmente, cerca de 250 espécies de lagartos que ocorrem, naturalmente, em seu território (BÉRNILS; COSTA, 2012). Esta grande riqueza, uma das maiores do mundo, resulta não apenas da elevada extensão territorial do país, mas, também, da diversidade de ecossistemas e de eventos históricos de mudanças climáticas e geográficas na América do Sul (ROCHA, 1994). Os lagartos ocorrem em praticamente todos os ambientes naturais brasileiros, e, inclusive, algumas espécies adaptaram-se eficientemente à vida em ambientes antrópicos (SILVA; ARAÚJO, 2008). Tendo em vista esta proximidade do cotidiano humano, é de se esperar que algumas espécies de lagartos tenham se tornado mais populares e figurem na cultura da população brasileira mais intensamente.

$\mathrm{Na}$ última década, têm crescido os registros acerca de concepções, conhecimentos, bem como usos de lagartos para fins: gastronômicos, farmacoterápicos e artesanais, por comunidades tradicionais no Brasil (ALVES, 2008; ALVES et al., 2012a; ALVES et al., 2012b; BARBOSA et al., 2007; COSTA NETO, 2000). No entanto, a expressão desses conhecimentos nas populações urbanas permanece pouco conhecida. Neste sentido, a existência de algumas espécies de lagartos adaptadas a ambientes antrópicos, somada à ascendência familiar de parcelas da população urbana, frequentemente relacionadas à zona rural, suporta a ocorrência de concepções particulares sobre lagartos nos centros urbanos.

Especificamente no âmbito educacional, tendo em vista que o contexto sociocultural é fundamental para a construção das concepções que influenciam a maneira de pensar e agir (COBERN, 1994), e que os conhecimentos prévios dos estudantes são importantes indicadores para que os professores redirecionem a prática pedagógica (GIORDAN, 1987), pesquisas recentes têm se voltado para a identificação de concepções culturais dos estudantes, com o intuito de integrá-las ao processo de ensino-aprendizagem (ALMEIDA, 2012; CARVALHO; COUTO; BOSSOLAN, 2012). Particularmente no caso dos répteis, dois recentes estudos investigaram as concepções prévias sobre anfisbenas e serpentes no âmbito educacional, revelando a importância da interação entre os conhecimentos popular e científico (BAPTISTA; COSTA NETO; VALVERDE, 2008; CASTRO; LIMA, 2013). Portanto, pesquisas deste tipo devem ser estimuladas, de modo a abrangerem outros grupos de animais, especialmente aqueles vistos com desprezo e antipatia por grande parte da sociedade, como os lagartos.

Neste trabalho, inventariamos concepções sobre lagartos segundo estudantes dos estágios finais da Educação Básica, avaliando sua relação com o atual estado do conhecimento científico e interpretando os casos em discordância. Estas informações possibilitam avaliar a eficiência do processo educacional sobre a biologia dos lagartos, permitindo a detecção de lacunas na construção do conhecimento sobre estes animais na Educação Básica. 


\section{Métodos}

O estudo foi conduzido em duas escolas da rede pública de ensino do município de Fortaleza, capital do estado do Ceará, Nordeste do Brasil. As escolas investigadas foram a Escola Estadual de Educação Profissional Joaquim Nogueira (344'21,44” S / 38 33'58,91'” W) e a Escola Estadual de Ensino Fundamental e Médio Joaquim Alves (345’33,10” S / 38³4’14,72”' W), ambas situadas nas proximidades do Campus do Pici da Universidade Federal do Ceará.

Considerando que as concepções culturais estão intrinsecamente relacionadas às características dos grupos ou comunidades que as produzem, apresentamos, a seguir, informações sobre os estudantes que permitem localizá-los socioculturalmente no espaço da cidade. Quanto à naturalidade dos informantes, $83 \%$ dos estudantes relataram serem naturais de Fortaleza. Em relação à filiação, $34 \%$ dos pais e $41 \%$ das mães dos estudantes eram de Fortaleza. Ao nível de ascendência de $2^{\circ}$ grau (avôs e avós), apenas 11\% eram naturais de Fortaleza. Provenientes de outros estados, foram somente 5\% dos pais (Maranhão e Paraíba), 4\% das mães (Maranhão e Piauí) e 17\% dos avós (Bahia, Maranhão, Mato Grosso e Paraíba). Portanto, a ascendência do grupo de estudo provém, predominantemente, de municípios do interior do estado do Ceará, o que permite inferir a existência de possíveis interações entre os estudantes e ambientes rurais. Quanto à ocupação profissional da filiação dos informantes, não houve predomínio de uma profissão entre os pais, mas 38\% das mães foram classificadas como profissionais do lar. Em geral, predominaram profissões de baixo poder aquisitivo (e.g. pedreiro, vendedor, costureira, manicure) e, em muitas famílias, apenas o pai contribuía para a renda familiar.

Para inventariar as concepções sobre lagartos presentes na comunidade estudantil, realizamos entrevistas semiestruturadas com estudantes do terceiro ano do Ensino Médio, nas quais os mesmos foram indagados sobre aspectos gerais relacionados a lagartos. As entrevistas semiestruturadas permitem que os informantes se expressem com liberdade sobre um determinado tema (LÜDKE; ANDRÉ, 1986), possibilitando a obtenção de informações esperadas, bem como aspectos não previstos (HUNTINGTON, 1998). O terceiro ano do Ensino Médio foi escolhido por representar o estágio final da Educação Básica brasileira e, portanto, aquele que apresenta estudantes com maior experiência educacional. Embora as entrevistas semiestruturadas apresentem uma estrutura básica, sua aplicação é flexível, permitindo, ao entrevistador, fazer adaptações e suplementos necessários. Nesta pesquisa, foi elaborado um roteiro-guia com tópicos elementares para direcionar a abordagem ao longo das entrevistas. O roteiro incluiu aspectos gerais relacionados a concepções, conhecimentos e usos tradicionais de lagartos, enfocando os seguintes temas principais, agrupados em 11 categorias: crenças, atividade diária, alimentação, comportamento, hábitat, interações interespecíficas, periculosidade, reprodução, superstição, uso gastronômico e uso farmacoterápico.

Para testes de verificação de consistência e validação das respostas, foram realizadas entrevistas sincrônicas e diacrônicas. Entrevistas sincrônicas ocorrem quando as mesmas perguntas são feitas a informantes diferentes em tempos próximos; já as diacrônicas ocorrem quando uma mesma pergunta é feita ao mesmo informante em tempos distintos (COSTA NETO, 2000). As entrevistas foram aplicadas em duas etapas de cinquenta minutos de duração, em cada turma investigada. O intervalo de tempo entre as etapas foi de 15 dias. Durante cada etapa, foram registradas tanto as respostas às indagações do roteiro-guia, como, também, eventuais contribuições espontâneas dos informantes. O registro das informações compartilhadas pelos 
informantes foi feito in situ, por gravação sonora (formato .mp3), com um gravador digital. A gravação foi utilizada por possibilitar o registro imediato e com exatidão de todas as expressões orais dos informantes, permitindo, ao entrevistador, a realização simultânea do registro das informações bem como a execução das entrevistas.

Os conhecimentos inventariados da comunidade estudantil foram analisados qualitativamente, com a elaboração de um "Quadro de Cognição Comparada", na qual trechos das entrevistas foram comparados com informações disponíveis na bibliografia científica (MARQUES, 1991), de modo a inferir sua coerência com o atual estado do conhecimento científico. Os dados coletados nesta pesquisa foram adquiridos sob o atendimento das exigências legais definidas na Resolução No 196/96 do Conselho Nacional de Saúde (BRASIL, 1996), que fornece as diretrizes e normas regulamentadoras de pesquisas envolvendo seres humanos. Para aquisição da autorização individual de cada informante, um Termo de Consentimento Livre e Esclarecido (TCLE) foi submetido a cada estudante que, espontaneamente, concordasse em participar da pesquisa. O TCLE garante a confidencialidade e a privacidade do informante, permitindo, ao sujeito, se recusar a participar ou retirar seu consentimento em qualquer fase da pesquisa.

\section{Resultados e discussão}

Ao todo, 38 estudantes (17 do sexo masculino e 21 do sexo feminino), com idade aproximada de vinte anos, participaram das entrevistas e declararam consentimento em participar desta pesquisa. Entre as informações compartilhadas, foram identificadas 85 concepções distintas sobre lagartos, das quais 72 foram agrupadas nas categorias previamente estabelecidas, e 13 outras contribuições foram analisadas separadamente, por não se relacionarem com nenhuma das categorias prévias. As frequências absolutas de concepções por categoria estão representadas no Gráfico 1.

Neste gráfico, a categoria “outras" engloba as concepções que não se relacionaram com nenhuma das categorias previamente determinadas. Nenhum tipo de crença envolvendo lagartos foi relatado. Além disso, embora existam registros do uso de lagartos para finalidades mágicas e religiosas, como o caso do "Tamaquaré" amazônico (Uranoscodon superciliosus (Linnaeus, 1758)) (ALVES, 2008), nenhuma concepção relacionada a estes fins foi registrada. Dentre as categorias registradas, merece destaque a relacionada com aspectos comportamentais, cuja representatividade correspondeu a 21,2\% do total de concepções. Muitas das concepções inventariadas apresentaram coerência com os conhecimentos científicos atuais, como demonstrado no Quadro de Cognição Comparada (Quadro 1).

Entretanto, existiram algumas incongruências em relação à bibliografia científica, que são exemplificadas e discutidas a seguir:

Quanto à atividade diária, surgiram concepções equivocadas sobre algumas espécies particulares: "O Tejo é um deles" (de hábito noturno). Nesta sentença, a espécie popularmente conhecida como "Tejo" (provavelmente, Tupinambis merianae, Duméril \& Bibron, 1839) é referida como de hábitos noturnos. Entretanto, isto não condiz com a bibliografia científica, uma vez que esta espécie é diurna, realizando suas atividades durante as horas mais quentes do dia (VAN SLUYS; ROCHA, 1999; VITT, 1995; WINCK; BLANCO; CECHIN, 2011).

Quanto aos aspectos comportamentais, também houve registro de equívocos de cunho biológico: "Quando o lagarto perde o rabo, ele só tem três dias de vida". A autotomia caudal, a capacidade 
Passos, D. C. et al.

Gráfico 1. Quantificação das concepções sobre lagartos por categoria temática, segundo estudantes de Ensino Médio de Fortaleza, Ceará, Brasil

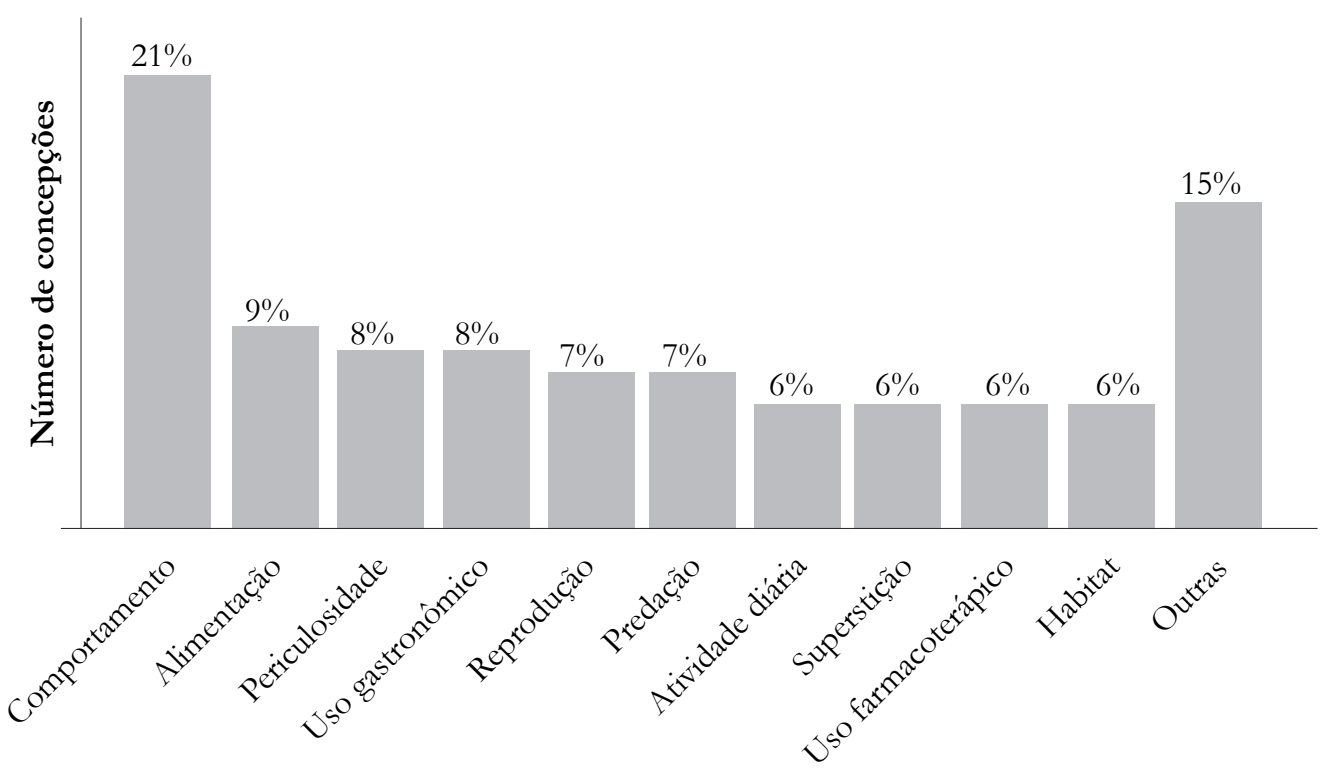

Categorias de concepções

Fonte: Elaborado pelos autores.

de voluntariamente desprender a cauda do corpo, é um reconhecido mecanismo de defesa contra predadores, utilizado por várias espécies de lagartos (SILVA; ARAÚJO, 2008). Esta estratégia de defesa apresenta custos associados, como a diminuição da taxa de crescimento durante a regeneração da cauda, redução do investimento reprodutivo e perda de reservas energéticas e de status social (ROCHA, 1994). Entretanto, de forma geral, a autotomia caudal não acarreta a morte do lagarto, em vez disso, a cauda pode ser perdida e regenerada consecutivas vezes.

Quanto a interações interespecíficas, só houve relatos de predação: "Gato que come lagarto morre seco". Lagartos constituem presas naturais de diversas classes de predadores, como: caranguejos, aranhas, serpentes, aves, mamíferos, entre outras. Embora apresentem, em geral, pequeno porte, os lagartos representam uma valiosa fonte de alimento para diversos animais (SILVA; ARAÚJO, 2008). Neste sentido, a predação de lagartos por gatos domésticos (Felis sp.), interação frequente em ambientes urbanos, normalmente não acarreta nenhuma alteração fisiológica prejudicial ao felino.

Quanto à periculosidade, destacam-se as concepções que atribuem, aos lagartos, o rótulo de potenciais causadores de dano aos humanos, especialmente as que fazem referência à capacidade de produção e inoculação de veneno: "As mordidas dos lagartos podem ser venenosas" e "Calango cego quando morde uma pessoa é pior que Cascavel". A referida espécie "Calango-cego" (provavelmente, Polychrus acutirostris Spix, 1825) é inofensiva ao ser humano, usando o comportamento deimático de exibir a boca aberta, cujo palato é preto, para intimidar potenciais ame- 
Quadro 1. Cognição Comparada apresentando concepções inventariadas em coerência com fontes da bibliografia científica referente a aspectos da biologia e história natural de lagartos

\begin{tabular}{|c|c|}
\hline Declarações dos informantes & Informações da bibliografia científica \\
\hline \multicolumn{2}{|r|}{ Alimentação } \\
\hline $\begin{array}{l}\text { Já presenciei um Calango comendo } \\
\text { escorpião, barata. }\end{array}$ & $\begin{array}{l}\text { A maioria dos lagartos brasileiros estudados consome uma dieta } \\
\text { composta, sobretudo, por artrópodes (SILVA; ARAÚJO, 2008). }\end{array}$ \\
\hline Iguana come folha. & $\begin{array}{l}\text { Os adultos da espécie Iguana iguana (Linnaeus, 1758) são } \\
\text { herbívoros (SILVA; ARAÚjO, 2008). }\end{array}$ \\
\hline O Tejo se alimenta de ovos também. & $\begin{array}{l}\text { Sobre os “Tejos" (Tupinambis): "Sua dieta é onívora, constituindo- } \\
\text { se de invertebrados, pequenos vertebrados (até peixes), ovos, } \\
\text { frutos e carniça" (VANZOLINI; RAMOS-COSTA; VITT, 1980, } \\
\text { p. 124). }\end{array}$ \\
\hline \multicolumn{2}{|r|}{ Atividade diária } \\
\hline A maioria dos lagartos são diurnos. & $\begin{array}{l}\text { Vitt (1995) constatou que } 11 \text { das } 13 \text { espécies investigadas de } \\
\text { lagartos da Caatinga eram diurnas. }\end{array}$ \\
\hline A Briba é o lagarto que anda de noite. & $\begin{array}{l}\text { Sobre a "Briba" (Hemidactylus mabouia (Moreau de Jonnès, } \\
\text { 1818), Vitt et al. (2008) caracterizam-na como noturna, não } \\
\text { heliotérmica. }\end{array}$ \\
\hline $\begin{array}{l}\text { Os lagartos andam toda hora, de } \\
\text { manhã, de noite. }\end{array}$ & $\begin{array}{l}\text { Lagartos podem ser ativos durante o dia, durante a noite ou em } \\
\text { ambos os turnos (SILVA; ARAÚJO, 2008). }\end{array}$ \\
\hline \multicolumn{2}{|r|}{ Comportamento } \\
\hline $\begin{array}{l}\text { Eles [os Calangos] ficam se olhando } \\
\text { e balançando a cabeça. }\end{array}$ & $\begin{array}{l}\text { Tropidurídeos têm uma corte elaborada, envolvendo flexões do } \\
\text { corpo e da cabeça (CARPENTER, 1977). }\end{array}$ \\
\hline $\begin{array}{l}\text { Tem um tipo de lagarto que se finge de } \\
\text { morto. }\end{array}$ & $\begin{array}{l}\text { A imobilidade tônica, ou tanatose, é um mecanismo defensivo } \\
\text { com o qual a presa, ao simular morte, desestimula o ataque do } \\
\text { predador (ROCHA, 1994). }\end{array}$ \\
\hline $\begin{array}{l}\text { Quando você vai pegar neles [nos } \\
\text { Calangos], eles deixam o rabo cair, } \\
\text { que épra despistar nossa atenção e ele } \\
\text { fugir. }\end{array}$ & $\begin{array}{l}\text { "A capacidade de voluntariamente desprender a cauda do corpo, } \\
\text { é um reconhecido mecanismo de defesa contra predadores, } \\
\text { utilizado por várias espécies de lagartos" (ROCHA, 1994, p. 52). }\end{array}$ \\
\hline
\end{tabular}

aças (VITT; LACHER JR., 1981). Assim, não há razões para rotulá-lo como perigoso e, muito menos, comparar suas ações com as graves consequências fisiológicas derivadas de um acidente ofídico crotálico (por cascavéis). Além disso, em todo o mundo, só existem três espécies de 
Quadro 1. continuação

\begin{tabular}{|c|c|}
\hline Declarações dos informantes & Informações da bibliografia científica \\
\hline \multicolumn{2}{|r|}{ Habitat } \\
\hline $\begin{array}{l}\text { Depende da espécie, tem calangos, mais } \\
\text { grosseiros, que preferem o mato, já a } \\
\text { bribinha, fica em casa. }\end{array}$ & $\begin{array}{l}\text { "Os lagartos são animais adaptáveis que ocupam habitats que } \\
\text { variam de pântanos a desertos e até mesmo acima da faixa de } \\
\text { florestas, em algumas montanhas" (POUGH; JANIS; HEISER, } \\
\text { 2008, p. 330). }\end{array}$ \\
\hline $\begin{array}{l}\text { Com certeza ele [o Calango] se } \\
\text { adaptou, saiu do habitat dele pra ir } \\
\text { pra região urbana. }\end{array}$ & $\begin{array}{l}\text { Há casos de espécies de lagartos que são favorecidas pelas } \\
\text { atividades humanas, por exemplo, em áreas perturbadas (SILVA; } \\
\text { ARAÚJO, 2008). }\end{array}$ \\
\hline As bribas rastejam pelas paredes. & $\begin{array}{l}\text { Hemidactylus mabouia (Moreau de Jonnès, 1818)) está fortemente } \\
\text { associado a áreas perturbadas, sendo comumente encontrado em } \\
\text { edificações humanas (ÁVILA-PIRES, 1995). }\end{array}$ \\
\hline \multicolumn{2}{|r|}{ Predação } \\
\hline $\begin{array}{l}\text { Eles [lagartos] servem de alimento } \\
\text { para alguns pássaros. }\end{array}$ & $\begin{array}{l}\text { "As aves são os principais predadores de lagartos diurnos de } \\
\text { pequeno a médio porte" (PIANKA; VITT, 2006, p. 64, tradução } \\
\text { nossa). }\end{array}$ \\
\hline As cobras comem lagartos. & $\begin{array}{l}\text { Lagartos são presas importantes na dieta de muitas serpentes em } \\
\text { diferentes biomas (SILVA; ARAÚJO, 2008). }\end{array}$ \\
\hline Os gatos comem lagartos & $\begin{array}{l}\text { "Durante os períodos de inatividade, mamíferos noturnos são } \\
\text { provavelmente os principais predadores de lagartos" (PIANKA; } \\
\text { VITT, 2006, p. 64, tradução nossa). }\end{array}$ \\
\hline \multicolumn{2}{|r|}{ Reprodução } \\
\hline Eu já vi um lagarto gestante/grávido. & $\begin{array}{l}\text { A viviparidade evoluiu em, pelo menos, } 45 \text { linhagens de lagartos } \\
\text { (ZUG; VITT; CALDWELL, 2001). }\end{array}$ \\
\hline Os lagartos, em geral, são ovíparos. & A maioria dos lagartos tropicais põe ovos (VITT et al., 2008). \\
\hline Os ovos de Calango parecem borracha & $\begin{array}{l}\text { A estrutura da casca varia consideravelmente entre os répteis } \\
\text { ovíparos (ZUG; VITT; CALDWELL, 2001). }\end{array}$ \\
\hline
\end{tabular}

Fonte: Elaborado pelos autores.

lagartos peçonhentos. Duas destas pertencem ao gênero Heloderma, os renomados "Monstros de Gila”, que ocorrem no Sudoeste da América do Norte (ZUG; VITT; CALDWELL, 2001), e a terceira, o famoso "Dragão de Komodo" (Varanus komodoensis Ouwens, 1912), a maior espécie de lagarto vivente, cuja distribuição natural é limitada a algumas ilhas na Indonésia (PIANKA; VITT, 2006). Portanto, não existem espécies de lagartos peçonhentos no Brasil. 
O conjunto de relatos supracitados reflete a falta de informação e a existência de concepções equivocadas na comunidade estudada. Isto pode ser evidência de falhas no processo de ensino-aprendizagem de Ciências e Biologia na Educação Básica, demonstrando que os professores e os materiais didáticos não forneceram informações básicas suficientes para instruir a comunidade estudantil sobre o ambiente natural à sua volta. Além disso, concepções errôneas, em especial quanto à periculosidade, geram sensações antipáticas em relação aos lagartos, como medo, repugnância e aversão, que, por consequência, podem promover reações e atitudes prejudiciais à sobrevivência das populações de lagartos no ambiente urbano.

A superstição também figurou entre as concepções inventariadas, sempre relacionada a eventos de azar e maus presságios: "Se você corta o rabo de uma lagartixa, terá sete anos de azar"e "Matar Calango traz azar". O azar, nestes casos, sempre é obtido como consequência de maus-tratos aos lagartos, o que configura uma perspectiva positiva no âmbito da conservação biológica, uma vez que induz a redução das taxas de mortalidade destes animais por humanos. Na Ásia, também existem crenças a respeito de as lagartixas atraírem má sorte (MAHENDRA, 1936). De forma geral, estas superstições, associadas às concepções de periculosidade e ao sentimento de medo, podem contribuir para que sejam evitadas atitudes agressivas com estes animais.

$\mathrm{O}$ uso de lagartos na gastronomia, seja como ingrediente principal ou acessório, foi bem reportado pelos informantes. Entre as respostas obtidas, surgiram relatos do consumo de lagartos, tanto por familiares quanto pelos próprios estudantes: "Meu avô comia Tejo"e "Eu já comi Camaleão, é comum no interior". Pelo menos duas espécies de lagartos nativos foram incluídos na dieta humana, o "Tejo" (Tupinambis merianae Duméril \& Bibron, 1839) e o "Camaleão" (Iguana iguana (Linnaeus, 1758)), que constituem as duas maiores espécies de lagartos na Caatinga, podendo atingir cerca de 1,5 m de comprimento (VANZOLINI; RAMOS-COSTA; VITT, 1980), fato que pode justificar sua grande importância cinegética (ALVES et al., 2012a). Répteis representam uma importante fonte de proteínas para populações humanas em diversas partes do mundo (ALVES et al., 2012a). No Brasil, pelo menos 38 espécies de répteis são consumidas como alimento e, destas, sete são lagartos (ALVES et al., 2012a). Merecem destaque os “Tejos" (Tupinambis) e os "Camaleões" (Iguanas), que têm seu consumo registrado, também, em centros urbanos (MARQUES; GUERREIRO, 2007).

Além do registro do consumo, houve, também, a caracterização do alimento consumido, com detalhes sobre o sabor e possíveis consequências de sua ingestão: "Eu já comi Tejo e tem gosto de frango" e "A pessoa que come Tejo e tem alguma ferida, a carne do Tejo faz abrir a ferida, é reimoso". Como se pode observar, à carne do "Tejo" (Tupinambis) é atribuído o sabor semelhante à de frango, como já registrado na bibliografia (ALVES et al., 2012a). Lagartos dos gêneros Tupinambis e Iguana são caçados para fins alimentares em vários países da América do Sul, e seu consumo e comercialização são comuns na América tropical (FITZGERALD, 1994; KLEMENS; THORBJARNARSON, 1995). Não obstante, entre os registros dos informantes, tanto em relação ao "Tejo" quanto ao "Camaleão", surgiram adjetivações de carne "reimosa", ou seja, que faz algum mal à saúde.

O emprego de lagartos ou parte deles para fins terapêuticos também foi registrado entre os estudantes: "A banha é usada para dor de garganta" (do "Tejo") e "O sangue pingado do rabo do Calango é bom pra sarar feridas e pra verrugas também”. A medicina popular é amplamente conhecida pelo uso de produtos de origem vegetal e animal, e várias espécies de répteis são usadas em farmacopeias em todo o mundo (ALVES; VIEIRA; SANTANA, 2008). No Brasil, répteis são 
usados na medicina tradicional desde os tempos pré-coloniais (ALVES; ROSA; SANTANA, 2007). Atualmente, pelo menos 54 espécies de répteis são usadas para propósitos medicinais no Brasil, e, destes, 13 são lagartos (ALVES et al., 2012a). Aqui, registra-se o uso da "banha" (camada de gordura) e do sangue de lagartos como zooterápicos, respectivamente para inflamações na garganta e cicatrização de lesões e verrugas. A gordura do "Tejo" (Tupinambis merianae Duméril \& Bibron, 1839) constitui um dos produtos zooterápicos mais usados na Caatinga, sendo utilizada para o tratamento de várias doenças (ALVES et al., 2009) e, inclusive, foi testada farmacologicamente quanto à sua atividade anti-inflamatória (FERREIRA et al., 2010). Além disso, o uso do "Calango" (Tropidurus hispidus (Spix, 1825)) no combate a verrugas também já foi registrado para comunidades sertanejas no Nordeste brasileiro (BARBOSA et al., 2007).

Além dos assuntos já discutidos, foram relatadas 13 concepções não relacionadas com nenhuma das categorias temáticas previamente definidas. Estes temas adicionais são exemplificados e discutidos a seguir.

A criação de espécies silvestres como animais de estimação tem aumentado nas últimas décadas. Experiências de manejo e domesticação de lagartos foram relatadas pelos informantes, inclusive a criação destes animais em cativeiro: "Meu pai já criou um Tejo" e "O pessoal pega o Camaleão e amarra uma cordinha no pescoço, pra criar". Cerca de vinte espécies de répteis são usadas como animais de estimação no Brasil, e os "Tejos" (Tupinambis) e as "Iguanas" (Iguana) constituem os principais representantes entre os lagartos (ALVES et al., 2012a). Entretanto, a maioria destes animais silvestres é adquirida de forma ilegal e a sua criação pode gerar problemas ecológicos, derivados da soltura dos indivíduos em ambientes naturais inadequados, especialmente quando se trata de espécies exóticas (ALVES et al., 2012a).

As espécies exóticas, por sua vez, também estiveram presentes nas contribuições dos informantes: "Existe um lagarto que voa de uma árvore para outra". Esta frase se refere ao "Lagarto voador" (Draco volans Linnaeus, 1758), espécie de lagarto tropical que plana no ar para se deslocar entre árvores (MCGUIRE; DUDLEY, 2011). "A saliva do Dragão de Komodo é venenosa”, aqui se faz menção ao famoso Varanus komodoensis Ouwens, 1912, a maior espécie de lagarto vivente (FRY et al., 2009). "Existe um Calango que anda sobre a água", neste caso, comenta-se sobre o curioso modo de deslocamento dos lagartos do gênero Basiliscus, que são capazes de se locomover sobre a superfície de corpos d'água (RAND; MARX, 1967). Comentários como estes podem ser justificados pela intensa influência da mídia, especialmente a televisão e a internet, demonstrando o potencial de instrução dos meios de comunicação em massa na formação dos estudantes.

A utilização de lagartos para ornamentação pessoal e decoração também foi contemplada pelos estudantes: "A pele, o couro do Tejo dá pra fazer bolsa". Nesta assertiva, observa-se o uso de recursos da fauna para a elaboração de adereços pessoais, o que, inclusive, possibilita a utilização destes animais para fins comerciais. Embora a caça dos “Tejos" (Tupinambis) geralmente ocorra devido aos danos que estes trazem para a avicultura (consumo de ovos e pintos), alguns subprodutos da caça podem ser usados para ornamentação (ALVES et al., 2012a). Em várias partes do mundo, ainda hoje, várias espécies de répteis são comercializadas para a confecção de bolsas, sapatos, cintos, entre outros artigos fabricados a partir de seus subprodutos (FITZGERALD et al., 2004).

As inferências taxonômicas reforçaram a competência dos informantes em reconhecer e nomear a biodiversidade que os cerca: "Os mais comuns são o Calango e a Briba". Além disso, diversos tipos de lagartos, como "Calango-cego", "Camaleão", "Lagartixa”, "Tejo" e "Tijubina”, foram identificados como espécies particularmente diferentes. Apesar da reconhecida 
imprecisão da nomenclatura popular, como relatado por Vanzolini, Ramos-Costa e Vitt (1980, p. 3): "Infelizmente, o caboclo nordestino, excelente botânico, é apenas um passável zoólogo e um péssimo herpetólogo", estes conhecimentos constituem evidências, ainda que limitadas, da classificação de répteis (etnotaxonomia) pelos estudantes. Isto demonstra a capacidade de reconhecer, distinguir e nomear várias espécies de lagartos pelos informantes, provavelmente, em função de suas origens rurais, de maneira similar ao que ocorre em outras comunidades tradicionais (VANZOLINI, 1956).

De especial relevância foi o compartilhamento de conhecimentos relacionados à importância direta dos lagartos para o homem: "Os lagartos são importantes porque eles comem os insetos maléficos pra gente, então eles comendo, diminuem mais esses bichos" e "Meu pai até gosta deles. Ele diæ: deixa os bichinhos ai que eles comem as baratas, as aranhas". Estas expressões revelam a consciência dos informantes sobre as reais funções dos lagartos no ambiente natural e, em especial, a valorização dos benefícios que estes trazem ao ser humano, sobretudo na zona urbana, com o controle populacional de organismos potencialmente prejudiciais à saúde.

Os resultados desta pesquisa evidenciaram a riqueza e diversidade de concepções, dentro e entre categorias, detidas pelos estudantes, demonstrando que estes apresentam relativa profundidade de conhecimento sobre diversos aspectos da biologia dos lagartos. Isto é um indício de que as concepções prévias dos estudantes merecem e devem ser consideradas ao longo do processo de ensino-aprendizagem, tanto para reestruturá-las quando em discordância com o atual estado do conhecimento científico, como para valorizá-las quando suplementam os conhecimentos fornecidos pela educação formal.

\section{Considerações finais}

A riqueza e a diversidade de concepções sobre lagartos detidas pelos estudantes evidenciaram que estes animais estão inseridos no contexto cultural dos informantes, figurando no cotidiano por meio de uma variedade de relações específicas. De forma geral, várias concepções apresentadas pelos estudantes foram coerentes com o atual estado do conhecimento científico sobre lagartos. Entretanto, a ocorrência de algumas concepções errôneas demonstra a existência de inconsistências teóricas em relação ao conteúdo biológico. Desse modo, a valorização do conhecimento popular e o esclarecimento das concepções equivocadas precisam ser estimulados ao longo da Educação Básica, no sentido de evitarem a propagação de relações conflituosas entre lagartos e seres humanos.

Tendo em vista a existência de concepções particulares sobre lagartos nas populações urbanas, a investigação das origens destes conhecimentos pode contribuir para o entendimento da manutenção destas expressões na cultura das cidades. Na perspectiva educacional, avaliar as origens destas concepções pode esclarecer quais meios de aquisição de informação (escolar, midiático ou social) estão propagando ideias equivocadas sobre estes animais. Consequentemente, esta compreensão pode fornecer diretrizes específicas para reorientar as fontes de informação, inclusive as ferramentas didáticas, no intuito de torná-las mais sintonizadas com o atual estado do conhecimento científico.

O conjunto complexo de concepções que os estudantes possuem sobre lagartos contribui para a nossa compreensão das representações sociais em relação a estes animais. Este valioso recurso cultural é essencial para entender o impacto das populações humanas urbanas 
sobre a fauna de lagartos. Portanto, uma vez considerada a importância dos lagartos para os humanos, dos pontos de vista ecológico, econômico e cultural, os produtos desta pesquisa forneceram subsídios para a valorização dos lagartos, além de reforçarem a necessidade da inclusão de ações de educação ambiental na Educação Básica, como ferramentas para enriquecerem o conhecimento básico sobre a biodiversidade, bem como esclarecerem e desmistificarem possíveis concepções errôneas.

\section{Agradecimentos}

Agradecemos aos informantes, pelo consentimento em compartilharem seus conhecimentos; aos professores e diretores das escolas investigadas, pela permissão do desenvolvimento desta pesquisa; a Hugo Fernandes-Ferreira e Daniel Cassiano Lima, pela revisão prévia deste trabalho. DCP também agradece à Fundação Carlos Chagas Filho de Amparo à Pesquisa do Estado do Rio de Janeiro, e LFM, à Coordenação de Aperfeiçoamento de Pessoal de Nível Superior (CAPES), pela concessão das respectivas bolsas de mestrado.

\section{Referências}

ALMEIDA, D. F. Concepções de alunos do Ensino Médio sobre a origem das espécies. Ciência \& Educação, Bauru, v. 18, n. 1, p. 143-154, 2012. Disponível em: < http:// www.scielo.br/pdf/ciedu/v18n1/09.pdf>. Acesso em: 27 out. 2014.

ALVES, R. R. N. Commercialization of uranoscodon superciliosus Linnaeus, 1758 (Tropiduridae) for magical-religious purposes in north and northeastern of Brazil. Sitientibus - Série Ciências Biológicas, Feira de Santana, v. 8, n. 2, p. 257-258, 2008.

ALVES, R. R. N. et al. Reptiles used for medicinal and magic religious purposes in Brazil. Applied Herpetology, Leiden, v. 6, n. 3, p. 257-274, 2009. . A review on human attitudes towards reptiles in Brazil. Environmental Monitoring and Assessment, Dordrecht, v. 184, n. 11, p. 6877-6901, 2012a. . A zoological catalogue of hunted reptiles in the semiarid region of Brazil. Journal of Ethnobiology and Ethnomedicine, London, v. 8, n. 1, p. 27-40, 2012b.

ALVES, R. R. N.; ROSA, I. L.; SANTANA, G. G. The role of animal-derived remedies as complementary medicine in Brazil. BioScience, Washington, v. 57, n. 11, p. 949-955, 2007.

ALVES, R. R. N.; SOUTO W. M. S. Ethnozoology in Brazil: current status and perspectives. Journal of Ethnobiology and Ethnomedicine, London, v. 7, n. 1, p. 7-22, 2011. 
ALVES, R. R. N.; VIEIRA,W. L. S.; SANTANA, G. G. Reptiles used in traditional folk medicine: conservation implications. Biodiversity and Conservation, Dordrecht, v.17, n. 8, p. 2037-2049, 2008.

ÁVILA-PIRES, T. C. S. Lizards of Brazilian Amazonia (Reptilia: Squamata). Zoologische Verhandelingen, Leiden, v. 299, n. 1, p. 1-706, 1995.

BAPTISTA, G. C. S.; COSTA NETO, E. M.; VALVERDE, M. C. C. Diálogo entre concepções prévias dos estudantes e conhecimento científico escolar: relações sobre os Amphisbaenias. Revista Iberoamericana de Educación, Madrid, v. 47, n. 2, p. 1-16, 2008. Disponível em: <http://www.rieoei.org/deloslectores/2394Baptista.pdf>. Acesso em: 27 out. 2014.

BARBOSA, A. R. et al. Abordagem etnoherpetológica de São José da Mata - Paraíba Brasil. Revista de Biologia e Ciências da Terra, João Pessoa, v. 7, n. 2, p. 117-123, 2007.

BÉRNILS, R. S.; COSTA, H. C. (Org.). Brazilian reptiles: list of species. Version 2012. Available in: <http://www.sbherpetologia.org.br/lista_repteis/ListaRepteis30Setembro2012INGLES.pdf>. Access on: 10 jan. 2013.

BRASIL. Conselho Nacional de Saúde. Diretrizes e normas regulamentadoras de pesquisas envolvendo seres humanos. Resolução 196/96. Disponível em: <http://www. ufrgs.br/bioetica/res19696.htm>. Acesso em: 20 out. 2013.

BROWN, D. E.; CARMONY, N. B. Gila monster: facts and folklore of America's Aztec lizard. Silver City: High-Lonesome Books, 1991.

CARPENTER, C. The agressive displays of three species of South American Iguanidae lizards of the genus Tropidurus. Herpetologica, Lawrence, v. 33, p. 285-289, 1977.

CARVALHO, J. C. Q.; COUTO, S. G.; BOSSOLAN, N. R. S. Algumas concepções de alunos do ensino médio a respeito das proteínas. Ciência \& Educação, Bauru, v. 18, n. 4, p. 897-912, 2012. Disponível em: <http://www.scielo.br/pdf/ciedu/v18n4/v18n4a10.pdf>. Acesso em: 27 out. 2014.

CASAS ANDREU, G. Mitos, leyendas y realidades de los reptiles de Mexico. Ciencia ErgoSum, Mexico, v. 7, n. 3, p. 286-291, 2000.

CASTILLO, F. Enciclopédia da vida selvagem Larousse: animais do deserto II.

Barcelona: Altaya, 1993.

CASTRO, D. P.; LIMA, D. C. Conhecimento do tema ofidismo entre futuros professores de ciências biológicas do estado do Ceará. Ciência \& Educação, Bauru, v. 19, n. 2, p. 393-407, 2013. Disponível em: <http://www.scielo.br/pdf/ciedu/v19n2/a11v19n2.pdf > . Acesso em: 27 out. 2014.

COBERN, W. W. Worldview, culture, and science education. Science Education International, Izmir, v. 5, n. 4, p. 5-8, 1994. 
Passos, D. C. et al.

COSTA NETO, E. M. Conhecimentos e usos tradicionais de recursos faunísticos por uma comunidade afro-brasileira: resultados preliminares. Interciência, Caracas, v. 25, n. 9, p. 423-431, 2000.

. Fulgora laternaria Linnaeus, 1758 (Hemiptera: Fulgoridae) na concepção dos moradores do povoado de Pedra Branca, Santa Terezinha, Bahia, Brasil. Revista de Ciências Ambientais, Canoas, v. 1, n. 1, p. 35-56, 2007.

FERREIRA, F. S. et al. Topical anti-inflammatory activity of body fat from the lizard Tupinambis merianae. Journal of Ethnopharmacology, Lausanne, v. 130, n. 3, p. 514-520, 2010.

FITZGERALD, L. A. Tupinambis lizards and people: a sustainable use approach to conservation and development. Conservation Biology, Boston, v. 8, n. 1, p. 12-16, 1994.

FITZGERALD L. A. et al. Collection, trade, and regulation of reptiles and amphibians of the Chihuahuan Desert ecoregion. Washington: Traffic North America, 2004.

FRANCHINI, A. S.; SEGANFREDO, C. As 100 melhores histórias da mitologia: deuses, heróis, monstros e guerras da tradição greco-romana. 9. ed. Porto Alegre: L\&PM, 2007.

FRY, B. G. et al. A central role for venom in predation by Varanus komodoensis (Komodo Dragon) and the extinct giant Varanus (Megalania) priscus. Proceedings of the National Academy of Sciences of the United States of America, Washington, v. 106, n. 22, p. 8969-8974, 2009.

GIORDAN, A. Los conceptos de biología adquiridos en el proceso de aprendizaje.

Enseñanza de las Ciencias, Barcelona, v. 5, n. 2, p. 105-110, 1987.

HART, G. The Routledge dictionary of Egyptian gods and goddesses. Abingdon: Routledge, 2005.

HUNTINGTON, H. P. Observations on the utility of the semi-directive interview for documenting traditional ecological knowledge. Arctic, Calgary, v. 51, n. 3, p. 237-242, 1998.

KLEMENS, M. W.; THORBJARNARSON, J. B. Reptiles as a food resource. Biodiversity \& Conservation, London, v. 4, n. 3, p. 281-298, 1995.

LEE, J. C. The amphibians and reptiles of the Yucatan Penninsula. Ithaca: Cornell University Press,1996.

LÜDKE, M.; ANDRÉ, M. E. D. A. Pesquisa em educação: abordagens qualitativas. São Paulo: E.P.U, 1986.

MAHENDRA, B. C. Geckos and superstition. Journal of Bombay Natural History Society, Mumbai, v. 88, p. 631-633, 1936.

MARQUES J. G. W. Aspectos ecológicos na etnoictiologia dos pescadores do complexo estuarino-lagunar Mundaú-Manguaba, Alagoas. 1991. 293 f. Tese

(Doutorado em Ecologia) - Instituto de Biologia, Universidade Estadual de Campinas, Campinas, 1991. 
; GUERREIRO, W. Répteis em uma feira nordestina (Feira de Santana, Bahia): contextualização progressiva e análise conexivo-tipológica. Sitientibus - Série Ciências Biológicas, Feira de Santana, v. 7, n. 3, p. 289-295, 2007.

MCGUIRE, J. A.; DUDLEY, R. The biology of gliding in flying lizards (genus Draco) and their fossil and extant analogs. Integrative and Comparative Biology, Mclean, v. 51, n. 6, p. 983-990, 2011.

PIANKA, E. R.; VITT, L. J. Lizards: windows to the evolution of diversity. Berkeley: University of California Press, 2006.

POUGH, H. F; JANIS, C. M.; HEISER, J. B. A vida dos vertebrados. São Paulo: Atheneu, 2008.

RAND, A. S.; MARX, H. Running speed of the lizard Basiliscus basiliscus on water. Copeia, Lawrence, v. 1967, n. 1, p. 230-233, 1967.

RAZERA, J. C. C.; BOCCARDO, L.; PEREIRA, J. P. R. Percepções sobre a fauna em estudantes indígenas de uma tribo tupinambá no Brasil: um caso de etnozoologia. Revista Electrónica de Enseñanza de las Ciencias, Vigo, v. 5, n. 3, p. 466-480, 2006. Disponível em: <http://reec.uvigo.es/volumenes/volumen5/ART5_Vol5_N3.pdf>. Acesso em: 27 out. 2014.

ROBERTS, A.; MOUNTFORD, C. P. The dreamtime: Australian aboriginal myths in paintings. Adelaide: Rigby, 1965.

ROCHA, C. F. D. Introdução à ecologia de lagartos brasileiros. In: NASCIMENTO, L. B.; BERNARDES, A. T.; COTTA; G. A (Org.). Herpetologia no Brasil, 1. Belo Horizonte: Fundação Biodiversitas, 1994. p. 39-57.

SHUKLA, H. L. Semiotica indica: encyclopaedic dictionary of body-language in indian art \& culture. Delhi: Aryan Books, 1994.

SILVA, S. G.; MANFRINATO, M. H. V.; ANACLETO, T. C. S. Morcegos: percepção dos alunos do ensino fundamental $3^{\circ}$ e $4^{\circ}$ ciclos e práticas de educação ambiental. Ciência $\boldsymbol{\&}$ Educação, Bauru, v. 19, n. 4, p. 859-877, 2013. Disponível em: < http://www.scielo.br/pdf/ ciedu/v19n4/v19n4a06.pdf>. Acesso em: 27 out. 2014.

SILVA, V. N.; ARAÚJO, A. F. B. Ecologia dos lagartos brasileiros. Rio de Janeiro: Technical Books, 2008.

THAPAR, R. A history of India. London: Penguin, 2006. v. 1.

UETZ, P. How many species? In: THE REPTILE database. Disponível em: < http://www. reptile-database.org/db-info/SpeciesStat.html>. Acesso em: 10 jan. 2013.

VAN SLUYS, M.; ROCHA, C. F. D. Tupinambis merianae (Common Tegu) activity.

Herpetological Review, Lawrence, v. 30, n. 1, p. 42-43, 1999. 
Passos, D. C. et al.

VANZOLINI, P. E. Notas sôbre a zoologia dos índios Canela. Revista do Museu Paulista, São Paulo, v. 10, p. 155-171, 1956.

; RAMOS-COSTA, A. M. M.; VITT, L. J. Répteis das caatingas. Rio de Janeiro: Academia Brasileira de Ciências, 1980.

VITT, L. J. The ecology of tropical lizards in the caatinga of northeast Brazil. Occasional Papers of the Oklahoma Museum of Natural History, Norman, v. 1, p. 1-29, 1995.

; CALDWELL, J. P. Herpetology: an introductory biology of amphibians and reptiles. 3rd. ed. Burlington: Elsevier, 2008.

; LACHER JR., T. E. Behavior, habitat, diet, and reproduction of the iguanid lizard Polychrus Acutirostris in the caatinga of northeastern Brazil. Herpetologica, Lafayette, v. 37, n. 1, p. 53-63, 1981.

VITT, L. et al. Guia de lagartos da reserva Adolpho Ducke, Amazônia Central. Manaus: Áttema Design Editorial, 2008.

WINCK, G.; BLANCO, C.; CECHIN, S. Population ecology of Tupinambis merianae (Squamata,Teiidae): home-range, activity and space use. Animal Biology, Amsterdam, v. 61, n. 4, p. 493-510, 2011.

ZUG, G. R.; VITT, L. J.; CALDWELL, L. P. Herpetology: an introductory biology of amphibians and reptiles. 2nd. ed. San Diego: Academic Press, 2001. 